\title{
Segurança hídrica do reservatório Castanhão-CE: aplicação da matriz de sistematização institucional
}

\author{
Water safety on Castanhão reservoir, Ceará, Brazil: \\ application of institutional systematization matrix
}

\author{
Eduardo Galdino de Souza', Ticiana Marinho de Carvalho Studart², \\ Maria Inês Teixeira Pinheiro ${ }^{3}$, José Nilson Bezerra Campos ${ }^{4}$
}

\section{RESUMO}

A segurança hídrica envolve o uso sustentável ea proteção dos sistemas hídricos, de modo a se dispor de água em quantidade e qualidade adequadas à saúde, aos meios de subsistência, aos ecossistemas e à produção. No que se refere à gestão da quantidade de água, houve muitos avanços desde a aprovação da Política Nacional de Recursos Hídricos em 1997. As competências e atribuições de cada ente do sistema estão definidas na legislação pertinente. No que se refere à gestão da qualidade de água, no entanto, há um grande número de normativos aplicáveis e de instituições competentes para atuarem na fiscalização e na regulação da matéria. Em função dessa gama de informações, configurase a necessidade de sistematização e síntese do arcabouço legal/institucional. Para essa finalidade, este trabalho propõe associar a metodologia da matriz de sistematização institucional aos instrumentos de monitoramento ambiental já praticados no Ceará. Espera-se que essa associação propicie visualizar as fontes potencialmente poluidoras, os normativos pertinentes e as instituições competentes. A metodologia foi aplicada ao reservatório Castanhão, no estado do Ceará. Identificou-se que $50 \%$ das fontes poluidoras são geradas por entidades públicas (Companhia de Água e Esgoto do Ceará - CAGECE; Serviço Autônomo de Água e Esgoto - SAAE; ou prefeituras municipais). As fontes particulares (pessoas físicas ou jurídicas) contribuem com os outros 50\%. Isso significa que ações de controle sobre entidades públicas poderiam resolver em grande parte a poluição da bacia hidrográfica. As agências reguladoras e os órgãos ambientais independentes podem contribuir muito para a redução das fontes de poluição.

Palavras-chave: segurança hídrica; matriz de sistematização institucional; fontes de poluição.

\begin{abstract}
Water security involves sustainable use and water system protection, in order to have water in quantity and quality acceptable to the health, livelihoods, ecosystems and production. Regarding water quantity management, many advances have occurred since the approval of the Brazilian Water Resources Policy in 1997. The competences and responsibilities of each entity of the system are defined in the relevant legislation. Regarding water quality management, however, there is a large number of applicable regulations and competent institutions to act in the supervision and regulation of the matter. Due to this range of information, the need to systematize and synthesize the legal/institutional framework is configured. For this finality, this work proposes to associate the institutional systematization matrix methodology with the environmental monitoring instruments already practiced in Ceará, Brazil. It is hoped that this association will allow the visualization of potentially polluting sources, relevant regulations and competent institutions. The methodology was applied to the Castanhão Reservoir, in the State of Ceará, Brazil. With this methodology, it was possible to identify that $50 \%$ of pollutant sources are generated by public entities (Companhia de Água e Esgoto do Ceará CAGECE; Serviço Autônomo de Água e Esgoto - SAAE; or city halls) and the other $50 \%$ correspond to individuals or legal entities. This means that control actions over public entities could solve an important part of the hydrographic basin pollution. Regulatory agencies and the independent environment entities can contribute to reduce pollution sources.
\end{abstract}

Keywords: water security; institutional systematization matrix; pollution sources.

\section{口}

1Doutorando do Programa de Pós-Graduação em Engenharia Civil Recursos Hídricos, Universidade Federal do Ceará (UFC) - Fortaleza (CE), Brasil.

2Professor titular no Programa de Pós-graduação em Engenharia Civil Recursos Hídricos, UFC - Fortaleza (CE), Brasil.

3Professor no Instituto Federal de Educação, Ciência e Tecnologia do Ceará (IFCe) - Fortaleza (CE), Brasil.

${ }^{4}$ Professor Titular no Programa de Pós-graduação em Engenharia Civil Recursos Hídricos, UFC - Fortaleza (CE), Brasil.

Endereço para correspondência: Eduardo Galdino de Souza - Avenida Humberto Monte, 2977 - Campus do Pici, PADETEC, Bloco 310, Galpão 11 - $60440-593$ - Fortaleza (CE),

Brasil - E-mail: eduardosaneamento@gmail.com

Recebido: 25/02/16 - Aceito: 28/07/17 - Reg. ABES: 363342 


\section{INTRODUÇÃO}

Estado mais seco do nordeste, o Ceará apresenta grande variabilidade temporal e espacial das precipitações e altas taxas de evaporação. O regime hidrológico de seus rios tem como característica marcante a intermitência intra-anual (CAMPOS; STUDART, 2008; PEREIRA; CUELLAR, 2015). Considerando ainda a predominância de solos cristalinos no estado, a disponibilidade hídrica para atender uma população de cerca de 9 milhões de habitantes está basicamente dependente dos estoques de água acumulados em reservatórios superficiais (CAMPOS et al., 2003). Atualmente, o estado do Ceará administra uma rede de 153 reservatórios, com capacidade total de acumulação de $18.674 \mathrm{hm}^{3}$ (FUNCEME, 2016).

Não obstante a importância dessa infraestrutura, diversas atividades antrópicas nas bacias de contribuição vêm degradando a qualidade da água desses reservatórios. O lançamento de esgotos domésticos sem tratamento adequado, a aplicação de agrotóxicos nas áreas de vazante, o lançamento de resíduos sólidos e de diversos rejeitos oriundos das atividades humanas, por exemplo, degradam muito as águas dos reservatórios.

Assim, é importante que se busquem estratégias de gestão de água que tenham foco na recuperação e na preservação do corpo hídrico, em especial de suas nascentes, visando à sustentabilidade da bacia (BOMFIM et al., 2015). Muitos autores têm contribuído no entendimento dos problemas de degradação de corpos hídricos associados aos diferentes usos do solo da bacia (PEREIRA et al., 2016; SOUZA, 2014; SOUZA; GASTALDINI, 2014).

Nesse sentido, a Companhia de Gestão de Recursos Hídricos do Ceará (COGERH) desenvolveu o Inventário Ambiental do Açude (IVA), que tem por objetivo levantar, sistematizar e confrontar informações relacionadas à qualidade da água dos reservatórios, com foco no processo de eutrofização. O IVA é uma poderosa ferramenta para a gestão da qualidade de água do reservatório, dado que identifica as fontes potencialmente poluidoras na bacia (COGERH, 2011).

A COGERH já desenvolveu o IVA para 30 reservatórios do estado. Identificadas as fontes poluidoras, pode-se conhecer as instituições com competências, definidas em lei, para fiscalizar e regular a matéria.

São muitas as instituições envolvidas e legislações aplicáveis. Na busca do entendimento e da sistematização da relação entre os processos de poluição e as competências institucionais para sua regulamentação e fiscalização, Pinheiro (2015) desenvolveu a metodologia matriz de sistematização institucional (MSI) e a aplicou na bacia do Açude Acarape do Meio, no Ceará, com $241 \mathrm{~km}^{2}$.

Neste trabalho, pretende-se construir a MSI para a bacia hidrográfica do reservatório Castanhão, principal fonte de água para a região metropolitana de Fortaleza (RMF), Ceará. Utilizam-se informações levantadas pelo IVA (COGERH, 2011), atualizadas pelo Sistema Nacional de Informação de Saneamento (SNIS, 2014) e pelo Perfil Básico Municipal (IPECE, 2015).

Considerando-se que a construção do IVA é prática corrente da COGERH, a metodologia aqui aplicada poderá ser estendida aos demais grandes reservatórios cearenses que dispõem de IVA, agregando uma ferramenta valiosa para a gestão da qualidade de suas águas.

\section{METODOLOGIA}

\section{Área de estudo}

O reservatório Castanhão está localizado na bacia hidrográfica do Jaguaribe, principal rio cearense. Com capacidade de acumular 6,7 bilhões de $\mathrm{m}^{3}$, que representam aproximadamente $35 \%$ da capacidade total de armazenamento do Ceará, o Castanhão é a principal fonte hídrica para a garantia da irrigação no Vale do Jaguaribe e para o abastecimento das cidades do Baixo Jaguaribe, da RMF e do Complexo Industrial e Portuário do Pecém (CIPP) (Figura 1). Trata-se do maior reservatório do Brasil, não pertencente ao sistema hidrelétrico (SRH, 2002).

\section{A metodologia matriz de sistematização institucional}

A MSI foi desenvolvida por Pinheiro (2015) com o intuito de criar uma metodologia que, a partir da identificação da fonte poluidora, sistematizasse a relação entre os processos de poluição e as competências institucionais. A MSI (Quadro 1) apresenta, nas linhas, os tipos de

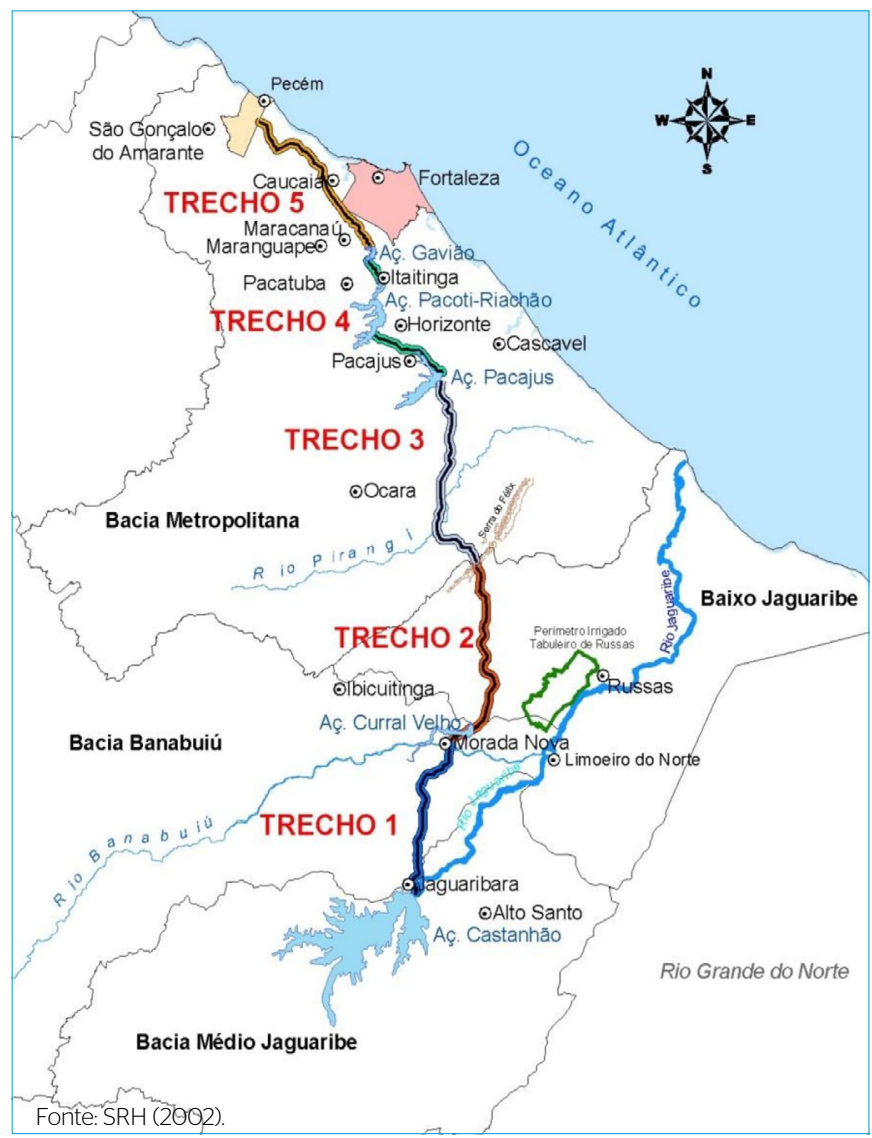

Figura 1 - Mapa esquemático do eixo de integração, reservatório Castanhão, região metropolitana de Fortaleza, Ceará (trechos de 1 a 5). 
fontes de poluição e, nas colunas, a tipologia dos agentes geradores e os componentes institucionais e legais.

\section{Identificação das fontes potencialmente poluidoras}

A MSI classifica a fonte de poluição em: pontual, difusa ou mista. As fontes pontuais são aquelas nas quais os poluentes são lançados de forma individualizada e em pontos específicos da bacia sendo, portanto, claramente identificáveis. São oriundas de efluentes de estação de tratamento de água e esgotos, efluentes industriais, cemitérios, matadouros, postos de serviços (postos de combustíveis, lava-jatos, oficinas mecânicas) e serviços de saúde (hospitais, postos de saúde e clínicas). As fontes difusas não têm um ponto de lançamento específico ou não advêm de um ponto preciso de geração, sendo de difícil controle e identificação, como as originadas da agricultura e aquicultura (piscicultura e carcinicultura). As fontes mistas englobam características de cada uma das fontes anteriormente descritas e são oriundas do escoamento superficial urbano, da pecuária e dos resíduos sólidos urbanos.

Quadro 1 - Formulário para sistematização da matriz institucional das fontes potencialmente poluidoras.

\begin{tabular}{|c|c|c|c|c|c|c|c|c|c|}
\hline 1 & 2 & & & 3 & & 4 & 5 & & \\
\hline \multirow{2}{*}{$\begin{array}{l}\text { Tipo de } \\
\text { fonte de } \\
\text { poluiçãão }\end{array}$} & \multicolumn{2}{|c|}{$\begin{array}{l}\text { Classificação da } \\
\text { fonte de poluição }\end{array}$} & \multicolumn{3}{|c|}{$\begin{array}{l}\text { Tipologia do agente } \\
\text { gerador da poluição }\end{array}$} & \multirow{2}{*}{$\begin{array}{l}\text { Agente } \\
\text { fiscalizador }\end{array}$} & \multirow{2}{*}{$\begin{array}{l}\text { Agente } \\
\text { regulador }\end{array}$} & \multicolumn{2}{|c|}{$\begin{array}{l}\text { Lançamento de } \\
\text { efluentes em corpo hídrico }\end{array}$} \\
\hline & $\begin{array}{l}\text { Fonte de } \\
\text { poluição }\end{array}$ & Serviço & Classe & Subclasse & $\begin{array}{l}\text { Agente } \\
\text { gerador }\end{array}$ & & & $\begin{array}{l}\text { Licença } \\
\text { ambiental }\end{array}$ & Outorga \\
\hline \multirow{13}{*}{ Pontual } & \multirow{3}{*}{$\begin{array}{l}\text { Efluente } \\
\text { de esgoto } \\
\text { doméstico }\end{array}$} & Público & & & & & & & \\
\hline & & Privado & & & & & & & \\
\hline & & $\begin{array}{c}\text { Sistema } \\
\text { individual }\end{array}$ & & & & & & & \\
\hline & $\begin{array}{l}\text { Efluente de Esg. } \\
\text { Ind. }\end{array}$ & Privado & & & & & & & \\
\hline & Efluente de & Público & & & & & & & \\
\hline & $\begin{array}{c}\text { tratamento de } \\
\text { água }\end{array}$ & Privado & & & & & & & \\
\hline & Comitério & Público & & & & & & & \\
\hline & 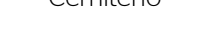 & Privado & & & & & & & \\
\hline & A Rotodour & Público & & & & & & & \\
\hline & tivica & Privado & & & & & & & \\
\hline & $\begin{array}{c}\text { Posto de } \\
\text { serviços (lava- } \\
\text { jato, posto de } \\
\text { combustíveis, } \\
\text { oficina de } \\
\text { veículos) }\end{array}$ & Privado & & & & & & & \\
\hline & $\begin{array}{l}\text { Serviço de } \\
\text { saúde (hospitais, }\end{array}$ & Público & & & & & & & \\
\hline & $\begin{array}{l}\text { postos de saude } \\
\text { e clínicas) }\end{array}$ & Privado & & & & & & & \\
\hline & Agricultura & Privado & & & & & & & \\
\hline Difusa & $\begin{array}{c}\text { Aquicultura } \\
\text { (carcinicultura } \\
\text { piscicultura) }\end{array}$ & Privado & & & & & & & \\
\hline Mista & $\begin{array}{c}\text { Escoamento } \\
\text { superficial } \\
\text { urbano }\end{array}$ & Público & & & & & & & \\
\hline & Pecuária & Privado & & & & & & & \\
\hline & Resíduo sólido & Público & & & & & & & \\
\hline
\end{tabular}


Para a aplicação da MSI no Castanhão, considerou-se que as fontes potencialmente poluidoras existentes no entorno do açude são aquelas identificadas quando da elaboração do IVA do reservatório (COGERH, 2011).

\section{Identificação do arcabouço legal}

Para a aplicação da MSI, foram consideradas as normas elencadas a seguir. Ao aplicar-se a MSI, é possível identificar os entes geradores de poluição, bem como as instituições com atribuições legais para regular e fiscalizar os agentes poluidores identificados:

- legislações que criam e regulamentam a Política Nacional dos Resíduos Sólidos e a Política Nacional de Saneamento Básico: Lei no 12.305/2010 (BRASIL, 2010a) e Lei no 11.445/2007 (BRASIL, 2007);

- legislações pertinentes ao lançamento de efluentes: Resolução COEMA 02/2017, do Conselho Estadual do Meio Ambiente (COEMA, 2017); Resolução do Conselho Nacional do Meio Ambiente no 357/2005 (CONAMA, 2005) e suas alterações que tratam da classificação dos corpos hídricos de acordo com seus usos pretendidos;

- regulamentação para implantação e funcionamento de cemitérios: Resolução CONAMA n 335/2003 (CONAMA, 2003) e suas alterações que tratam das especificações técnicas em que os cemitérios devem se enquadrar para funcionamento sem prejuízos ao meio ambiente;

- legislação sobre as sanções penais e administrativas, derivadas de condutas e atividades lesivas ao meio ambiente: Lei no 9.605/1998 (BRASIL, 1998).

\section{Atualização dos dados do Inventário Ambiental do Açude}

Para atualizar os dados do IVA do Castanhão, no que se refere à cobertura dos serviços de água e esgotos dos municípios do seu entorno, foram consultados o Sistema Nacional de Informação de Saneamento (SNIS, 2014) e o Perfil Básico Municipal (IPECE, 2015). A cobertura de limpeza urbana foi atualizada pelo Perfil Básico Municipal 2015 (IPECE, 2015). Foram feitas, ainda, visitas às secretarias de meio ambiente dos municípios de Nova Jaguaribara e Jaguaretama.

\section{RESULTADOS E DISCUSSÃO}

Observa-se, na Tabela 1, que todos os municípios do entorno do reservatório têm excelente cobertura de abastecimento de água da área urbana (72,9 a 100\%). Porém, assim como os demais municípios brasileiros, são deficientes em termos de rede de coleta e tratamento de esgotos, drenagem e coleta de resíduos sólidos (SNIS, 2014; COGERH, 2011; IPECE, 2015). As empresas responsáveis pelos serviços de saneamento nos municípios são a Companhia de Água e Esgoto do Ceará (CAGECE) e o Serviço Autônomo de Água e Esgoto (SAAE).

Dentre os quatro municípios do entorno do reservatório, apenas Nova Jaguaribara tem mais da metade da população atendida pela coleta de esgotos; Jaguaribe e Jaguaretama têm 23,2 e 2,2\% da população atendida, respectivamente, e em Alto Santo a coleta é inexistente. Todo o esgoto coletado nos três municípios é tratado (SNIS, 2014).

Observa-se, ainda, que a drenagem é considerada satisfatória apenas em Nova Jaguaribara (COGERH, 2011). Os municípios apresentam também de baixo a moderado índice (entre 41,7 e 75,2\%) de cobertura de limpeza urbana (IPECE, 2015).

Esses números retratam um delicado problema social e ambiental, uma vez que a ineficiência no acesso a serviços básicos de saneamento está associada a maiores índices de doenças, com os corpos hídricos transformados em destino final dos efluentes das diversas atividades humanas.

\section{Identificação das fontes potencialmente poluidoras}

As principais fontes potencialmente poluidoras identificadas no IVA do reservatório Castanhão (COGERH, 2011) são elencadas a seguir. Em cada item são relacionadas legislação pertinente e instituições envolvidas.

Tabela 1 - Cobertura dos serviços de saneamento básico nos municípios situados no entorno do reservatório Castanhão.

\begin{tabular}{|c|c|c|c|c|c|}
\hline \multirow{2}{*}{ Serviço } & \multicolumn{5}{|c|}{ Municipio } \\
\hline & & Alto Santo & Nova Jaguaribara & Jaguaretama & Jaguaribe \\
\hline Empresa responsável' ${ }^{1}$ & & CAGECE & CAGECE & CAGECE & SAAE \\
\hline \multirow{2}{*}{ Índice de atendimento de água' (\%) } & Urbano & 72,9 & 100 & 84,7 & 100 \\
\hline & Total & 35,8 & 69,3 & 40,1 & 99,4 \\
\hline Índice de coleta de esgotos ${ }^{1}(\%)$ & Total & 0,0 & 52,5 & 2,2 & 23,2 \\
\hline Índice de tratamento de esgotos ${ }^{1}(\%)$ & Total & 0,0 & 100 & 100 & 100 \\
\hline Limpeza urbana3 $(\%)$ & - & 41,7 & 75,2 & 48,2 & 66,2 \\
\hline Drenagem urbana² & - & Insatisfatória & Satisfatória & Insatisfatória & Insatisfatória \\
\hline
\end{tabular}

Fonte: 'SNIS (2014), ${ }^{2}$ COGERH (2011), ${ }^{3}$ PEECE (2015).

CAGECE: Companhia de Água e Esgoto do Ceará; SAAE: Serviço Autônomo de Água e Esgoto. 
O IVA não identificou a existência de fontes poluidoras relacionadas a efluentes industriais, matadouros, postos de serviços (lava-jatos, oficinas mecânicas, postos de combustíveis etc.) e serviços de saúde (hospitais, postos de saúde, clínicas).

\section{Efluente de esgoto doméstico}

O lançamento de água residuária de qualquer natureza é um dos principais fatores de poluição dos corpos hídricos, dado que aumenta a demanda bioquímica de oxigênio (DBO), a carga de nutrientes e a quantidade de patógenos no meio. Muitas vezes, a disposição dos efluentes é realizada sem considerar a capacidade de autodepuração do corpo hídrico, impactando de forma considerável o meio aquático, provocando o desequilíbrio ecológico do meio (RODRIGUES et al., 2015). Nesse caso, a água torna-se imprópria para os mais diversos usos, o que implica no aumento dos custos de tratamento para potabilizá-la.

Conforme já observado, a coleta de esgoto sanitário é bastante deficitária nas cidades do entorno do reservatório, com destaque especial para a cidade de Alto Santo, onde é inexistente. A população da cidade utiliza o sistema de fossa-sumidouro, ou lança os dejetos diretamente em vias públicas, rios ou riachos.

Segundo a legislação brasileira, dispor efluentes nos corpos hídricos não configura crime, desde que sejam obedecidos critérios de lançamento previstos nas normas vigentes. Na esfera federal, os critérios a serem atendidos constam na Resolução CONAMA nº 430/2011 (CONAMA, 2011), que complementa e altera a Resolução CONAMA $n^{\circ}$ 357/2005 (CONAMA, 2005) e dispõe sobre as condições e padrões de lançamento de efluentes.

A Resolução CONAMA nº 430/2011 (CONAMA, 2011), em seu artigo terceiro, no inciso primeiro do parágrafo único, ainda resolve que o órgão ambiental competente tem atribuição legal para acrescentar condições e padrões de lançamento de efluentes, podendo torná-los, inclusive, mais restritivos. Sendo assim, no âmbito do estado do Ceará, os padrões de lançamento são os contidos na Resolução COEMA 02/2017 (COEMA, 2017).

\section{Efluente de estações de tratamento de água e estações de tratamento de esgoto}

A CAGECE é responsável pelo abastecimento de água e coleta de esgoto nas cidades de Alto Santo, Jaguaretama e Nova Jaguaribara. Nesses municípios, a cobertura de água tratada não é total (de 35,8 a 69,3\%) e a coleta de esgotos é bastante deficiente (de 0 a 52,5\%). Em Jaguaribe, os serviços de saneamento são prestados pelo SAAE, com cobertura total de abastecimento de água na zona urbana e rural, e aproximadamente $23 \%$ de cobertura na coleta de esgotos (SNIS, 2014).

A Resolução COEMA no 10/2015 (COEMA, 2015) considera que as estações de tratamento de água (ETA) e estações de tratamento de esgoto (ETE) possuem de médio a alto potencial poluidor-degradador; as diretrizes nacionais para o saneamento básico estão contidas na Lei Federal no 11.445/2.007 (BRASIL, 2007), que estabelece que o município é o responsável por toda a logística de coleta, transporte, distribuição e destino dos efluentes gerados nas ETA e ETE.

A operação de sistemas de tratamento de água e esgotos necessita de licenciamento ambiental (licença de operação), a ser fornecida pela SEMACE, que também fiscaliza essa atividade, nos termos da Resolução COEMA 02/2017 (COEMA, 2017), obedecendo aos padrões de lançamento de efluentes estabelecidos pela Resolução CONAMA n 430/2011 (CONAMA, 2011). A fiscalização pode ser compartilhada com a Secretaria de Recursos Hídricos do Estado do Ceará (SRH), caso a prefeitura municipal ou a concessionária (CAGECE ou SAAE) solicitem outorga para o lançamento de efluentes no corpo hídrico, nos termos da Lei Estadual n $14.844 / 2010$ (CEARÁ, 2010).

Paralelamente à fiscalização, a SEMACE atua como agente regulador, juntamente com a Agência Reguladora dos Serviços Públicos Delegados do Estado do Ceará (ARCE), criada pela Lei Estadual $\mathrm{n}^{\circ}$ 12.786/1997 (CEARÁ, 1997). Sendo assim, a ARCE e a SEMACE regulam os serviços da CAGECE; no caso do SAAE, por ser uma autarquia municipal, a regulação fica a cargo do município. Vale ressaltar, no entanto, que Jaguaribe (atendido pelo SAAE) não possui agência reguladora dos serviços prestados pelo município.

\section{Cemitérios (necrochorume)}

O licenciamento ambiental de cemitérios é normatizado pela Resolução CONAMA no 335/2003 (CONAMA, 2003), alterada pela Resolução CONAMA n 368/2006 (CONAMA, 2006) e pela Resolução CONAMA nº 402/2008 (CONAMA, 2008). Nos termos da Resolução CONAMA $n^{\circ} 368 / 2006$, os cemitérios devem ser providos de sistema de drenagem para encaminhar e dispor, de forma ambientalmente correta, o necrochorume produzido (CONAMA, 2006). O IVA do Castanhão, no entanto, aponta que nenhum dos quatro municípios situados no entorno do reservatório possui sistema de drenagem em seus cemitérios. Segundo a Resolução CONAMA nº 402/2008, o limite para a adequação de cemitérios aos novos critérios seria o mês de dezembro do ano de 2010 (CONAMA, 2008), prazo há muito expirado.

Não existe base legal para atuação dos municípios como agentes fiscalizadores do setor de cemitérios. Esta atividade, pelo seu alto potencial poluidor-degradador (COEMA, 2015), necessita de licença ambiental (licenças prévia, de instalação e de operação), fornecida pelo órgão ambiental estadual (CONAMA, 2003), a qual poderá ser cassada ou suspensa, caso o exercício da atividade esteja em desacordo com as normas e padrões ambientais. A inobservância às disposições constantes na Resolução CONAMA no 335/2003 (CONAMA, 2003) sujeitará o infrator às penalidades previstas na Lei de Crimes Ambientais, n 9.605/1998 (BRASIL, 1998): multa diária, imediata reparação dos 
danos causados, recuperação da área do empreendimento, embargo do empreendimento e pena de um a cinco anos de reclusão - podendo-se dobrar esse período, conforme a gravidade do crime.

\section{Agricultura}

A prática da agricultura nas proximidades de um corpo hídrico significa riscos em potencial à qualidade da água do manancial (JARDIM; BURSZTYN, 2015). Os defensivos agrícolas na lavoura podem ser carreados pela água da chuva até um corpo hídrico. Pode-se afirmar que, em virtude da intercomunicabilidade, qualquer contaminante em um sistema hídrico pode ser detectado em um ponto distante do local de origem (DELLAMATRICE; MONTEIRO, 2014).

Já são bem conhecidos os efeitos neurológicos ocasionados pelo uso de água contaminada por agroquímicos. Citam-se: o desconforto visual, diminuição da concentração/vigilância, memória, coordenação motora, ansiedade e irritabilidade (FONTE; MOREIRA, 2010). A Resolução COEMA no 10/2015 classifica a atividade de agricultura, com o uso de defensivos agrícolas, como uma atividade de alto potencial poluidor-degradador (COEMA, 2015).

Nas cidades que circundam o reservatório Castanhão, a agricultura é realizada tanto por indivíduos isolados, pessoas físicas, como por pessoas jurídicas. Dependendo do porte do empreendimento, a implementação dessa atividade requer licença de operação a ser emitida pela SEMACE.

\section{Aquicultura}

Nos últimos 15 anos, o Ceará, com o apoio do Governo Federal, tem aproveitado seus grandes reservatórios para o desenvolvimento da aquicultura. Segundo Carioca et al. (2010), da área dos reservatórios do estado, cerca de $1 \%$ é destinado para essa atividade. A ideia é promover o aumento da produção de pescado e a inclusão social, melhorar a distribuição de renda, combater a pobreza e proporcionar melhoria nutricional da população (FEIDEN et al., 2015). A Food and Agriculture Organization (FAO), na 31 a Sessão do Comitê de Pesca, ocorrida em Roma, em 2014, recomendou o desenvolvimento de projetos similares em outros países (SOUZA, 2014).

Entretanto, a criação intensiva do pescado e camarão acarreta o lançamento do excesso de ração no corpo hídrico. Além disso, frequentemente realiza-se o tratamento do pescado, com evisceração, descamação e lavagem à beira do lago. O carreamento desses resíduos, ricos em nitrogênio e fósforo, contribui para a eutrofização do corpo hídrico (LOPES et al., 2010; MONTEIRO et al., 2016). No Castanhão, a produção de peixes é praticada por piscicultores isolados (indivíduos isolados, pessoas físicas) ou por entidades particulares, como empresas e associações (indivíduos agrupados, pessoas jurídicas).

O Conselho Estadual do Meio Ambiente (COEMA) classifica as atividades de aquicultura como de médio potencial poluidor-degradador, observando que, quando os efluentes daquelas atividades não forem dispostos adequadamente, tais atividades podem contribuir para a poluição de lagos e do solo (COEMA, 2015).

A aquicultura é fiscalizada pela SEMACE ou pela SRH. A atividade requer licença ambiental de instalação e operação, a ser emitida pela SEMACE (COEMA, 2015). Quando realizada nos açudes públicos, também é necessária uma outorga para acesso ao uso da água a ser emitida pela COGERH, conforme a Lei no 14.844/2010 (CEARÁ, 2010) e o Decreto Estadual no 30.629/2011 (CEARÁ, 2011).

\section{Escoamento superficial urbano}

A rede de drenagem pluvial é de responsabilidade das prefeituras, conforme a Lei Federal $n^{\circ}$ 11.445/2007 (BRASIL, 2007) e o Decreto Federal n 7.217/2010 (BRASIL, 2010b). É necessária a emissão de licença ambiental para que as prefeituras possam ofertar esse serviço à população. Tal licença é emitida pelo órgão ambiental do estado (SEMACE), que fiscaliza e regula a atividade em todo o Ceará.

\section{Pecuária}

A prática da pecuária também pode ser danosa ao meio ambiente, caso não sejam obedecidos critérios técnicos (CHRISTOFIDIS, 2013). Os rejeitos dessa atividade são depositados no solo e podem ser carreados até os corpos hídricos, contribuindo, assim, para o aumento de nutrientes no corpo hídrico, o que favorece a eutrofização (PEREIRA, 2012; CAPOANE et al., 2015).

Segundo a Resolução COEMA no 10/2015 (COEMA, 2015), é necessária a obtenção de licença ambiental de operação, para atuar no setor da pecuária, sem abate de animais. Essa atividade é considerada de médio potencial poluidor-degradador. Constatada, por parte do órgão ambiental, no caso a SEMACE, irregularidades por parte do empreendedor, a licença de operação é cassada ou suspensa.

Vale observar que as atividades agropastoris no Ceará requerem outorga para o uso da água, no sentido de se controlar a oferta e a demanda de água bruta e garantir a sustentabilidade do uso da água para múltiplos usos, conforme a Política Estadual de Recursos Hídricos, Lei n ${ }^{\circ}$ 14.844/2010 (CEARÁ, 2010) e o Decreto Estadual nº 30.629/2011 (CEARÁ, 2011)

\section{Resíduos sólidos}

No Brasil, apenas $40 \%$ dos municípios dispõem seus resíduos sólidos de forma adequada. Os $60 \%$ restantes realizam a disposição em aterros controlados ou em lixões (ABRELPE, 2014). A Lei no 12.305/2010, que criou a Política Nacional dos Resíduos Sólidos (BRASIL, 2010a), estabeleceu que os lixões fossem extintos, em todo o território nacional, até o final de 2015. Porém, dadas as dificuldades de recursos, a grande maioria dos municípios não cumpriu a meta estipulada pelo Governo Federal.

Está em tramitação no Congresso o Projeto de Lei (PL) n².289/2015 (BRASIL, 2015), que prorroga o prazo para que municípios passem a 
dar o destino adequado aos rejeitos de resíduos sólidos, fechem seus lixões e se ajustem de vez à Política Nacional de Resíduos Sólidos. A proposta prevê o aumento escalonado do prazo, de acordo com o porte da cidade.

Os municípios do entorno do reservatório Castanhão apresentam baixo índice de cobertura de limpeza urbana (42 a 66\%); apenas Nova Jaguaribara tem $88 \%$. Os mesmos dispõem seus resíduos sólidos domiciliares em lixões. Como não existe obediência a critérios ambientais na sua concepção, os lixões têm provocado contaminação do solo e dos recursos hídricos, uma vez que o chorume pode atingir o lençol freático e acarretar diversos problemas de saúde, em caso de contaminação por microrganismos ou mesmo intoxicações (FERREIRA et al., 2014).

De acordo com a Política Nacional dos Resíduos Sólidos (BRASIL, 2010a), a coleta e a disposição final dos resíduos sólidos domiciliares são de responsabilidade dos municípios. Nos termos da Lei Estadual $n^{\circ}$ 16.032/2016 (CEARÁ, 2016), cabe à SEMACE a fiscalização da atividade. Assim, a prefeitura necessita de licença ambiental para coleta e deposição dos resíduos sólidos. O COEMA classifica as atividades de coleta, transporte e armazenamento de resíduos sólidos de origem domiciliar como de alto risco poluidor-degradador (COEMA, 2015).

\section{Aplicação da matriz de sistematização institucional}

O IVA do Castanhão identificou oito tipos diferentes de fontes potencialmente poluidoras no entorno do lago. A Tabela 2 apresenta a MSI do reservatório Castanhão, com a classificação da fonte poluidora, a tipologia do agente gerador da poluição, o agente regulador, o agente fiscalizador e a necessidade (ou não) de licença e outorga pelo uso da água.

\section{Fontes poluidoras e agentes poluidores}

As fontes potencialmente poluidoras identificadas pelo IVA foram de oito tipos: efluentes de esgoto doméstico, efluentes de ETE e ETA, cemitérios, agricultura, aquicultura, escoamento superficial urbano, pecuária e resíduos sólidos. Não foi detectada poluição oriunda de efluentes industriais, matadouros, postos de serviços (lava-jatos, postos de combustíveis e oficinas mecânicas), e postos de serviços de saúde (hospitais, clínicas e postos de saúde). No caso de lançamento dos efluentes de ETA e ETE, os agentes geradores da poluição são a CAGECE e o SAAE; no caso de cemitérios, escoamento superficial urbano e resíduos sólidos, os agentes geradores da poluição são as prefeituras municipais. Nas fontes de poluição restantes, os agentes geradores de poluição são pessoas físicas e/ou jurídicas, pela disposição de efluentes domésticos em sistemas do tipo fossa-sumidouro, prática da agricultura, pecuária e aquicultura. Ou seja, em 12,5\% dos tipos de fontes potencialmente poluidoras identificadas na bacia, o agente poluidor é a concessionária de água-esgoto (CAGECE ou SAAE); em
$37,5 \%$ dos tipos, o agente poluidor é a prefeitura municipal e, em 50\% o agente é pessoa física ou jurídica (Figura 2). Sendo assim, 50\% dos agentes potencialmente poluidores são entidades públicas (CAGECE, SAAE ou prefeituras).

\section{Agentes fiscalizadores}

Quanto aos agentes fiscalizadores, observa-se que, nos oito tipos de fontes de poluição explicitados pela MSI, a responsabilidade pela fiscalização inclui a SEMACE. A competência de fiscalização também pode ser compartilhada com a SRH, em atividades como agropecuária, aquicultura e lançamento de efluentes de ETA e ETE, conforme a Lei no 14.844/2010 (CEARÁ, 2010).

Além dos dados do IVA, coletaram-se informações locais atualizadas. Observou-se a inexistência de fiscalização ambiental por parte das prefeituras municipais. De acordo com a Resolução CONAMA n ${ }^{\circ}$ 430/2011 (CONAMA, 2011), as prefeituras podem exercer a função de fiscalização do meio ambiente, caso possuam leis próprias. Os municípios de Alto Santo e Jaguaribe não possuem secretaria de meio ambiente nem leis ambientais próprias.

O município de Jaguaretama possui secretaria de meio ambiente, mas não tem legislação ambiental específica; todas as atividades de fiscalização e licenciamento ambiental ficam sob a responsabilidade da SEMACE.

O município de Nova Jaguaribara possui a Secretaria de Agricultura, Meio Ambiente e Recursos Hídricos e legislação ambiental própria: a Lei $n^{\circ}$ 450/2001 (NOVA JAGUARIBARA, 2001) e a Lei n537/2004 (NOVA JAGUARIBARA, 2004). Porém, por falta de infraestrutura, a prefeitura alega não poder exercer a função de fiscalização (informações levantadas em visita de campo). Para novos empreendimentos, a Secretaria de Agricultura, Meio Ambiente e Recursos Hídricos de Nova Jaguaribara fornece um Termo de Anuência que comprova que a obra está de acordo com as leis municipais de uso e ocupação do solo, Plano Diretor Municipal, etc.

\section{Agentes reguladores}

Observa-se que a SEMACE tem competência legal para a regulação de todas as atividades constantes no IVA do Castanhão, sendo que essa competência pode ser compartilhada com a ARCE, quando os efluentes são oriundos de ETA e ETE.

\section{CONCLUSÕES}

Foram identificados pela MSI oito tipos de fontes de poluição (efluentes de esgoto doméstico, efluentes de ETE e ETA, cemitérios, agricultura, aquicultura, escoamento superficial urbano, pecuária e resíduos sólidos) na bacia do Castanhão. Verificou-se que as fontes poluidoras do tipo difusas e mistas são predominantes na bacia $(62,5 \%)$, o que 
Tabela 2 - Matriz de sistematização institucional aplicada ao reservatório Castanhão.

\begin{tabular}{|c|c|c|c|c|c|c|c|c|c|}
\hline 1 & 2 & & & 3 & & 4 & 5 & & \\
\hline \multirow{2}{*}{$\begin{array}{l}\text { Tipo de } \\
\text { fonte de } \\
\text { poluição }\end{array}$} & \multicolumn{2}{|c|}{$\begin{array}{l}\text { Classificação da } \\
\text { fonte de poluição }\end{array}$} & \multicolumn{3}{|c|}{$\begin{array}{l}\text { Tipologia do agente } \\
\text { gerador da poluição }\end{array}$} & \multirow{2}{*}{$\begin{array}{l}\text { Agente } \\
\text { fiscalizador }\end{array}$} & \multirow{2}{*}{$\begin{array}{l}\text { Agente } \\
\text { regulador }\end{array}$} & \multicolumn{2}{|c|}{$\begin{array}{l}\text { Lançamento de efluentes } \\
\text { em corpo hídrico }\end{array}$} \\
\hline & $\begin{array}{l}\text { Fonte de } \\
\text { poluição }\end{array}$ & Serviço & Classe & Subclasse & $\begin{array}{l}\text { Agente } \\
\text { Gerador }\end{array}$ & & & $\begin{array}{l}\text { Licença } \\
\text { Ambiental }\end{array}$ & Outorga \\
\hline \multirow{13}{*}{ Pontual } & \multirow{3}{*}{$\begin{array}{l}\text { Efluente } \\
\text { de esgoto } \\
\text { doméstico }\end{array}$} & Público & $\begin{array}{c}\text { Entidade } \\
\text { pública }\end{array}$ & $\begin{array}{c}\text { Entidade } \\
\text { pública } \\
\text { indireta }\end{array}$ & $\begin{array}{c}\text { CAGECE } \\
\text { SAAE }\end{array}$ & $\begin{array}{c}\text { SEMACE } \\
\text { SRH }\end{array}$ & $\begin{array}{c}\text { ARCE } \\
\text { SEMACE }\end{array}$ & Sim & Sim \\
\hline & & Privado & Indivíduos & - & - & - & - & - & - \\
\hline & & $\begin{array}{l}\text { Sistema } \\
\text { Individual }\end{array}$ & Indivíduos & $\begin{array}{l}\text { Indivíduos } \\
\text { isolados (II) }\end{array}$ & Pessoa física & SEMACE & SEMACE & $\begin{array}{l}\text { Não se } \\
\text { aplica }\end{array}$ & $\begin{array}{l}\text { Não se } \\
\text { aplica }\end{array}$ \\
\hline & $\begin{array}{l}\text { Efluente } \\
\text { de esgoto } \\
\text { industrial }\end{array}$ & Privado & - & - & - & - & - & - & - \\
\hline & \multirow[t]{2}{*}{$\begin{array}{l}\text { Efluente de } \\
\text { ETA e ETE }\end{array}$} & Público & $\begin{array}{l}\text { Entidade } \\
\text { pública }\end{array}$ & $\begin{array}{c}\text { Entidade } \\
\text { pública } \\
\text { indireta }\end{array}$ & $\begin{array}{c}\text { CAGECE } \\
\text { SAAE }\end{array}$ & $\begin{array}{c}\text { SEMACE } \\
\text { SRH }\end{array}$ & $\begin{array}{c}\text { ARCE } \\
\text { SEMACE }\end{array}$ & Sim & Sim \\
\hline & & Privado & - & - & - & - & - & - & - \\
\hline & \multirow[t]{2}{*}{ Cemitério } & Público & $\begin{array}{c}\text { Entidade } \\
\text { pública }\end{array}$ & $\begin{array}{l}\text { Entidade } \\
\text { pública } \\
\text { direta ou } \\
\text { indireta }\end{array}$ & $\begin{array}{l}\text { Prefeitura } \\
\text { municipal }\end{array}$ & SEMACE & SEMACE & Sim & $\begin{array}{l}\text { Não se } \\
\text { aplica }\end{array}$ \\
\hline & & Privado & - & - & - & - & - & - & - \\
\hline & \multirow{2}{*}{ Matadouro } & Público & - & - & - & - & - & - & - \\
\hline & & Privado & - & - & - & - & - & - & - \\
\hline & $\begin{array}{l}\text { Posto de } \\
\text { serviços (lava- } \\
\text { jato, posto de } \\
\text { combustíveis, } \\
\text { oficina de } \\
\text { veículos) }\end{array}$ & Privado & - & - & - & - & - & - & - \\
\hline & Serviço & Público & - & - & - & - & - & - & - \\
\hline & $\begin{array}{l}\text { (hospitais, } \\
\text { postos de } \\
\text { saúde e } \\
\text { clínicas) }\end{array}$ & Privado & - & - & - & - & - & - & - \\
\hline \multirow[t]{2}{*}{ Difusa } & Agricultura & Privado & Indivíduos & $\begin{array}{l}\text { Indivíduos } \\
\text { isolados } \\
\text { ou } \\
\text { agrupados } \\
\text { (IA) }\end{array}$ & $\begin{array}{l}\text { Pessoa } \\
\text { Física } \\
\text { Pessoa } \\
\text { Jurídica }\end{array}$ & $\begin{array}{l}\text { SEMACE } \\
\text { SRH }\end{array}$ & SEMACE & Sim & Sim \\
\hline & $\begin{array}{c}\text { Aquicultura } \\
\text { (carcinicultura/ } \\
\text { piscicultura) }\end{array}$ & Privado & Indivíduos & $\begin{array}{l}\text { Indivíduos } \\
\text { Isolados ou } \\
\text { agrupados }\end{array}$ & $\begin{array}{c}\text { Pessoa física } \\
\text { Pessoa } \\
\text { jurídica }\end{array}$ & $\begin{array}{c}\text { SEMACE } \\
\text { SRH }\end{array}$ & SEMACE & Sim & Sim \\
\hline \multirow{4}{*}{ Mista } & $\begin{array}{c}\text { Escoamento } \\
\text { superficial } \\
\text { urbano }\end{array}$ & Público & $\begin{array}{c}\text { Entidade } \\
\text { pública }\end{array}$ & $\begin{array}{c}\text { Entidade } \\
\text { pública } \\
\text { direta ou } \\
\text { indireta }\end{array}$ & $\begin{array}{l}\text { Prefeitura } \\
\text { municipal }\end{array}$ & SEMACE & SEMACE & Sim & $\begin{array}{l}\text { Não se } \\
\text { aplica }\end{array}$ \\
\hline & Pecuária & Privado & Indivíduos & $\begin{array}{l}\text { Indivíduos } \\
\text { isolados } \\
\text { ou } \\
\text { agrupados }\end{array}$ & $\begin{array}{c}\text { Pessoa física } \\
\text { Pessoa } \\
\text { jurídica }\end{array}$ & $\begin{array}{l}\text { SEMACE } \\
\text { SRH }\end{array}$ & SEMACE & Sim & Sim \\
\hline & \multirow[t]{2}{*}{$\begin{array}{l}\text { Resíduos } \\
\text { sólidos }\end{array}$} & Público & $\begin{array}{l}\text { Entidade } \\
\text { pública }\end{array}$ & $\begin{array}{l}\text { Entidade } \\
\text { pública } \\
\text { direta ou } \\
\text { indireta }\end{array}$ & $\begin{array}{l}\text { Prefeitura } \\
\text { municipal }\end{array}$ & SEMACE & SEMACE & Sim & $\begin{array}{l}\text { Não se } \\
\text { aplica }\end{array}$ \\
\hline & & Privado & - & - & - & - & - & - & - \\
\hline
\end{tabular}

SAAE: Sistema Autônomo de Água e Esgoto; ETA: estação de tratamento de água; ETE: estação de tratamento de esgotos; SEMACE: Superintendência Estadual do Meio Ambiente; SRH: Secretaria dos Recursos Hídricos; CAGECE: Companhia de Água e Esgoto do Ceará; ARCE: Agência Reguladora dos Serviços Públicos Delegados do Estado do Ceará. (-) não existente na bacia. 


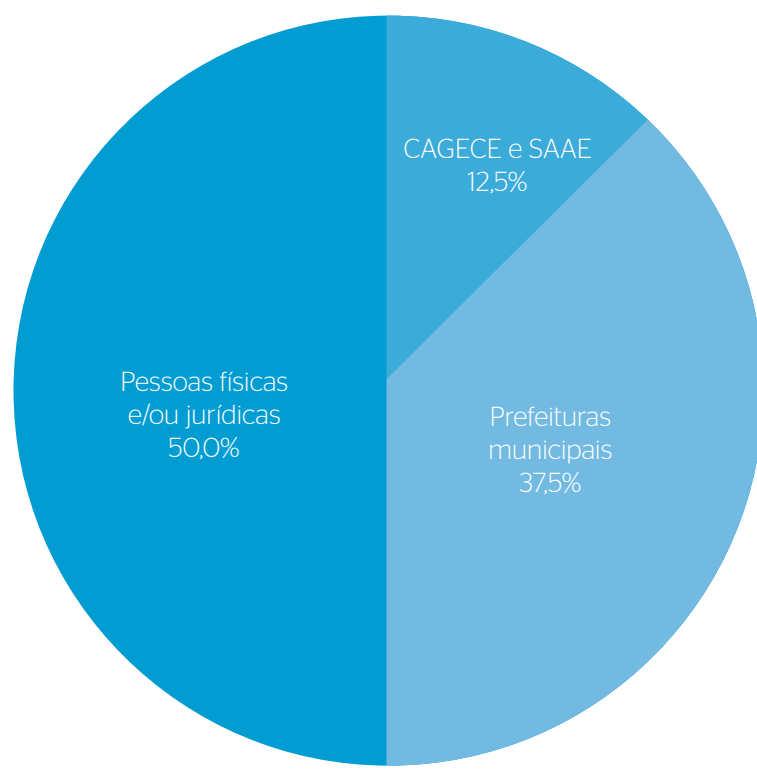

CAGECE: Companhia de Água e Esgoto do Ceará; SAAE: Serviço Autônomo de Água e Esgoto.

Figura 2 - Distribuição percentual dos agentes geradores de poluição responsáveis pelas oito fontes poluidoras apontadas pelo Inventário Ambiental do Açude na bacia do reservatório Castanhão.

representa um ponto negativo para a gestão, dado que essas fontes são mais difíceis de monitorar e controlar.

A MSI evidenciou que $50 \%$ dos agentes responsáveis pelas fontes poluidoras são entidades públicas (CAGECE, SAAE ou prefeituras municipais); os outros $50 \%$ correspondem a pessoas físicas ou jurídicas. Importante observar o fato de que a própria concessionária (CAGECE ou SAAE) polui o corpo hídrico usado para abastecimento humano.

Observou-se ainda que, em todos os tipos de fontes identificadas, de acordo com a legislação pertinente, compete à SEMACE a fiscalização do lançamento dos efluentes no corpo hídrico; em alguns casos a SRH pode exercer também o papel de agente fiscalizador.

Ao analisar-se a competência para fiscalizar e regular as atividades potencialmente poluidoras na bacia, constatou-se o papel primordial da SEMACE, que concentra as duas funções, podendo partilhar a função de fiscalização com a SRH, e a função de regular com a ARCE. Verificou-se, ainda, que a existência de secretaria de meio ambiente municipal não garante, necessariamente, a existência de leis ambientais locais próprias. Igualmente, a existência de lei ambiental municipal não garante que a prefeitura esteja efetivamente exercendo a função de agente fiscalizador. Há um descompasso entre as leis e as capacidades dos municípios de exercitá-las.

Observou-se que a utilização da MSI possibilitou elaborar um diagnóstico sucinto e objetivo dos principais problemas que afetam a qualidade das águas do reservatório Castanhão, e identificar os agentes poluidores, fiscalizadores e reguladores das atividades poluidoras.

Em síntese, a metodologia da MSI associada ao IVA constitui-se em valiosa ferramenta de gestão da qualidade da água dos grandes reservatórios do Ceará. Ademais, a MSI pode ser estendida a todos os reservatórios que possuem IVA.

\section{REFERÊNCIAS}

ASSOCIAÇÃO BRASILEIRA DE EMPRESAS DE LIMPEZA PÚBLICA RESÍDUOS ESPECIAIS - ABRELPE. (2004). Panorama dos Resíduos Sólidos no Brasil. São Paulo: Abrelpe.

BOMFIM, E. O.; GADELHA, C. L. M.; FIGUEIRA, H. J. A.; AMORIM, J. F.; AMORIM, D. S. (2015). Sustentabilidade hidroambiental de nascentes na bacia hidrográfica do rio Gramame no Estado da Paraíba, Brasil. Sociedade \& Natureza, Uberlândia, v. 27, n. 3, p. 453-468.

BRASIL. (1998). Casa Civil da Presidência da República, Subchefia de Assuntos Jurídicos. Lei no 9.605, de 12 de fevereiro de 1998. Dispõe sobre as sanções penais e administrativas derivadas de condutas e atividades lesivas ao meio ambiente, e dá outras providências. Brasília.

(2007). Casa Civil da Presidência da República, Subchefia de Assuntos Jurídicos. Lei no 11.445, de 5 de janeiro de 2007. Estabelece diretrizes nacionais para o saneamento básico; altera as Leis nos. 6.766, de 19 de dezembro de 1979, 8.036, de 11 de maio de 1990, 8.666, de 21 de junho de 1993, 8.987, de 13 de fevereiro de 1995; revoga a Lei n 6.528, de 11 de maio de 1978; e dá outras providências. Brasília.

(2010a). Casa Civil da Presidência da República, Subchefia de Assuntos Jurídicos. Lei no 12.305, de 2 de agosto de 2010. Institui a Política Nacional de Resíduos Sólidos; altera a Lei no 9.605, de 12 de fevereiro de 1998, e dá outras providências. Brasília.

(2010b). Presidência da República. Casa Civil. Subchefia para Assuntos Jurídicos. Decreto no 7.217, de 21 de junho de 2010. Regulamenta a Lei no 11.445, de 5 de janeiro de 2007, que estabelece diretrizes nacionais para o saneamento básico, e dá outras providências. Brasília.

(2015). Câmara dos Deputados. Projeto de Lei no 2.289/2015. Prorroga o prazo para a disposição final ambientalmente adequada dos rejeitos de que trata o art. 54 da Lei no 12.305, de 2 de agosto de 2010. Brasília. 
CAMPOS, J. N. B.; STUDART, T. M. C. (2008). Drought and water policies in Northeast Brazil: backgrounds and rationale. Water Policy, v. 10, n. 5, p. 425-438.

CAMPOS, J. N. B.; STUDART, T. M. C.; MARTINZ, D. D. G.; VASCONCELOS, L. S. V. (2003). Contribuições ao Debate Sobre as Eficiências de Pequenos e Grandes Reservatórios. Revista Brasileira de Recursos Hidricos, v. 8, n. 2.

CAPOANE, V:; TIECHER, T.; SCHAEFER, G.; CIOTTI, L. H.; SANTOS, D. R. (2015). Transferência de nitrogênio e fósforo para águas superficiais em uma bacia hidrográfica com agricultura e produção pecuária intensiva no Sul do Brasil. Ciência Rural, Santa Maria, v. 45, n. 4, p. 647-650.

CARIOCA, J. O. B.; FRIEDRICH, H.; EHRENBERGER, S. (2010). Sustainable Aquaculture for Microalgae, Biofuels and Feed Productions. In: INTERNATIONAL MICROALGAE AND BIOFUELS WORKSHOP. Anais... Fortaleza (CE).

CEARÁ. (1997). Governo do Estado do Ceará. Lei no 12.786, de 30 de dezembro de 1997. Institui a Agência Reguladora de Serviços Públicos Delegados do Estado do Ceará - ARCE, e dá outras providências. Ceará

(2010). Governo do Estado do Ceará. Lei no 14.844, de 28 de dezembro de 2010. Dispõe sobre a Política Estadual de Recursos Hídricos, Institui o Sistema Integrado de Gestão de Recursos Hídricos - SIGERH, e dá outras providências. Ceará.

CEARÁ. (2011). Governo do Estado do Ceará. Decreto Estadual no 30.629/2011. Ceará

(2016). Governo do Estado do Ceará. Lei no 16.032, de 20 de junho de 2016. Institui a Política Estadual de Resíduos Sólidos no âmbito do Estado do Ceará. Ceará.

CHRISTOFIDIS, D. (2013). Água, irrigação e agropecuária sustentável. Revista de Política Agrícola, ano 22, n. 1.

COMPANHIA DE GESTÃO DOS RECURSOS HÍDRICOS - COGERH. (2011). Inventário Ambiental do Açude Castanhão. Fortaleza: Governo do Estado do Ceará.

CONSELHO ESTADUAL DO MEIO AMBIENTE - COEMA. (2015). Resolução no 10, de 11 de junho de 2015. Dispõe sobre a atualização dos procedimentos, critérios, parâmetros e custos aplicados aos processos de licenciamento e autorização ambiental no âmbito da Superintendência Estadual do Meio Ambiente - SEMACE. Ceará: Coema.

(2017). Resolução no 02, de 2 de fevereiro de 2017. Dispõe sobre padrões e condições para lançamento de efluentes líquidos gerados por fontes poluidoras, revoga as Portarias SEMACE no 154, de 22 de julho de 2002, e no 111, de 5 de abril de 2011, e altera a Portaria SEMACE no 151, de 25 de novembro de 2002. Ceará: COEMA.

CONSELHO NACIONAL DO MEIO AMBIENTE - CONAMA. (2003). Resolução no 335, de 3 de abril de 2003. Dispõe sobre o licenciamento ambiental de cemitérios. Brasília: Ministério do Meio Ambiente.
(2005). Resolução no 357, de 17 de março de 2005. Dispõe sobre a classificação dos corpos de água e diretrizes ambientais para o seu enquadramento, bem como estabelece as condições e padrões de lançamento de efluentes, e dá outras providências. Brasília: Ministério do Meio Ambiente.

(2006). Resolução no 368, de 28 de março de 2006. Altera dispositivos da Resolução no 335, de 3 de abril de 2003, que dispõe sobre o licenciamento ambiental de cemitérios. Brasília: Ministério do Meio Ambiente.

(2008). Resolução no 402, de 17 de novembro de 2008. Altera os arts. 11 e 12 da Resolução CONAMA n० 335/2003, do Conselho Nacional do Meio Ambiente - CONAMA. Brasília: Ministério do Meio Ambiente.

(2011). Resolução no 430, de 13 de maio de 2011. Dispõe sobre as condições e padrões de lançamento de efluentes, complementa e altera a Resolução no 357, de 17 de março de 2005, do Conselho Nacional do Meio Ambiente - CONAMA. Brasília: Ministério do Meio Ambiente.

DELLAMATRICE, P. M.; MONTEIRO, R. T. R. (2014). Principais aspectos da poluição de rios brasileiros por pesticidas Revista Brasileira de Engenharia Agrícola e Ambiental, v. 18, n. 12, p. 1296-1301.

FEIDEN, I. F.; OLIVEIRA, J. D. S.; DIEMER, O.; FEIDEN, A. (2O15) Qualidade da água, capacidade de suporte e melhor período para criação de peixes em tanques-rede no reservatório de Salto Caxias. Engenharia Sanitária e Ambiental, v. 20, n. 4 p. 589-594.

FERREIRA, R. F.; MENDONÇA, A. P.; CUZZOUL, E. R.; NASCIMENTO, E. L.; STACHIW, R.; FERREIRA, E. (2014). Análise microbiológica e direção do fluxo subterrâneo do lixão desativado em Ji-Paraná, Rondônia. Revista Brasileira de Ciências da Amazônia, v. 3, n. 1, p. 37-46.

FONTE, C. F. V.; MOREIRA, J. C. (2010). Effects of glyfosagte and 2,4 D on earth worms in laboratory tests. Bull Environmental Contamination Toxicology, v. 85, n. 3, p. 264-268.

FUNDAÇÃO CEARENSE DE METEOROLOGIA E RECURSOS HIIDRICOS - FUNCEME. Página virtual. Disponível em: <http://www. funceme.br/\#todospelaagua>. Acesso em: 14 nov. 2016.

INSTITUTO DE PESQUISA E ESTATISTTICA ECONÔMICA DO CEARÁ - IPECE. (2015). Perfil básico municipal. Disponível em: <http://www. ipece.ce.gov.br/index.php/perfil-basico-municipal-2015>. Acesso em: jan. 2017.

JARDIM, M. H.; BURSZTYN, M. A. (2015). Pagamento por serviços ambientais na gestão de recursos hídricos: o caso de Extrema (MG). Engenharia Sanitária e Ambiental, v. 20, n. 3, p. 353-360.

LOPES, P. S.; NOGUEIRA, A. K. M.; BRAGA, E. A. S.; SANTOS, F. F. P. AQUINO, M. D. (2010). Análise do impacto ambiental causado pelo descarte das vísceras de peixe no açude Castanhão e perspectivas de seu aproveitamento para produção de biodiesel. In: ENCONTRO NACIONAL DOS GEÓGRAFOS: CRISE, PRÁXIS E AUTONOMIA: ESPAÇOS DE RESISTÊNCIAS E DE ESPERANÇA, ESPAÇO DE DIÁLOGO E PRÁTICAS, 16., 2010, Porto Alegre. Anais... Porto Alegre: AGB. 
MONTEIRO, L. S.; BORGES, D. A.; STUDART, T. M. C.; CAMPOS, J. N. B.; MOTA, F. S. B. (2016). Calculation method for charging water on shrimp farming. Revista Brasileira de Recursos Hidricos, v. 21, n. 4. DOI: http://dx.doi.org/10.1590/2318-0331.011615006

NOVA JAGUARIBARA. (2001). Lei no 450 de 20/11/2001. Dispõe sobre a Política Ambiental do Município de Jaguaribara, Unidades de Conservação e dá outras providências. Nova Jaguaribara.

(2004). Lei no 537/2004. Dispõe sobre a criação do Conselho Municipal de Defesa do Meio Ambiente. Nova Jaguaribara.

PEREIRA, B. W. F.; MACIEL, M. N. M.; OLIVEIRA, F. A.; ALVES, M. A. M. S.; RIBEIRO, A. M.; FERREIRA, B. M.; RIBEIRO, E. G. P. (2016). Uso da terra e degradação na qualidade da água na bacia hidrográfica do rio Peixe-Boi, PA, Brasil. Ambiente \& Água, Taubaté, v. 11, n. 2.

PEREIRA, G. R.; CUELLAR, M. D. Z. (2015). Conflitos pela água em tempos de seca no Baixo Jaguaribe, Estado do Ceará. Estudos Avançados, v. 29, n. 84. DOI: 10.1590/S0103-40142015000200008

PEREIRA, S. L. (2012). Pecuária bovina de corte no Estado do Pará: água, impactos ambientais e sustentabilidade ambiental. Dissertação (Mestrado) - Programa de Pós-Graduação em Engenharia Civil, Instituto de Tecnologia, Universidade Federal do Pará, Belém.

PINHEIRO, M. I. T. (2015). Segurança da Água em Bacias Hidrográficas: Formulação de um Modelo Institucional. Tese
(Doutorado) - Programa de Pós-Graduação em Engenharia Civil Recursos Hídricos, Universidade Federal do Ceará, Fortaleza.

RODRIGUES, A. M.; SILVA JÚNIOR, E. D.; SALEH, B. B. (2015). Estudo qualitativo da água do Ribeirão Campo Alegre mediante influência da Estação de Tratamento de Esgoto da cidade de Santa Helena de Goiás. Revista Eletrônica em Gestão, Educação e Tecnologia Ambiental, Santa Maria, v. 19, n. 3, p. 752-760.

SECRETARIA DOS RECURSOS HÍDRICOS - SRH. (2002). EixO de Integração Castanhão - Fortaleza. Sintese dos Estudos. Fortaleza: SRH.

SISTEMA NACIONAL DE INFORMAÇÃO DE SANEAMENTO - SNIS. (2014). Ministério das Cidades. Página Virtual. Disponível em: <http://www.snis.gov.br/>. Acesso em: jan. 2017.

SOUZA, E. G. (2014). Geração de biodiesel e biogás a partir dos residuosdoprocessamento de tilápiado Nilo(Oreochromisniloticus). Dissertação (Mestrado) - Departamento de Engenharia Hidráulica e Ambiental, Programa de Pós-Graduação em Engenharia Civil: Saneamento Ambiental, Centro de Tecnologia, Universidade Federal do Ceará, Fortaleza.

SOUZA, M. M.; GASTALDINI, M. C. C. (2014). Avaliação da qualidade da água em bacias hidrográficas com diferentes impactos antrópicos. Engenharia Sanitária e Ambiental, v. 19, n. 3, p. 263-274. 